PREPARED FOR THE U.S. DEPARTMENT OF ENERGY, UNDER CONTRACT DE-AC02-76CH03073

PPPL-3748

PPPL-3748

UC-70

Parametric Investigation of Miniaturized Cylindrical and Annular Hall Thrusters

by

A. Smirnov, Y. Raitses, and N.J. Fisch

September 2002

$\left.\stackrel{M}{M}\right|_{\substack{\text { PRInCETON PLASIMA } \\ \text { PHYSICS LABORATORY }}} ^{D}$

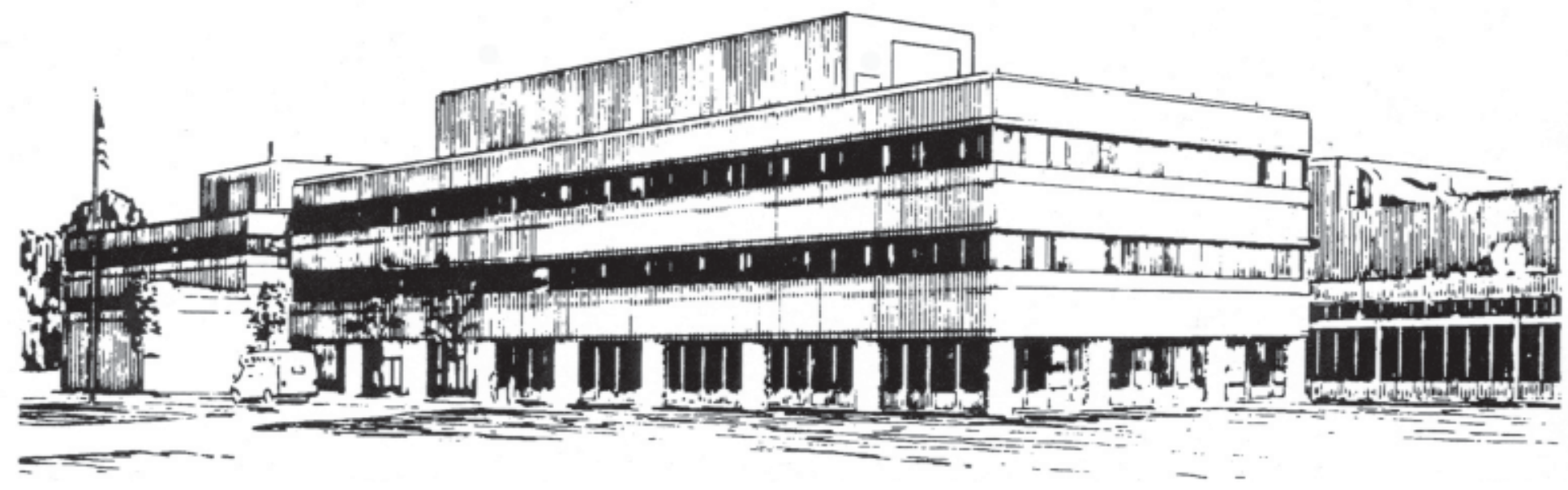

PRINCETON PLASMA PHYSICS LABORATORY PRINCETON UNIVERSITY, PRINCETON, NEW JERSEY 


\section{PPPL Reports Disclaimer}

This report was prepared as an account of work sponsored by an agency of the United States Government. Neither the United States Government nor any agency thereof, nor any of their employees, makes any warranty, express or implied, or assumes any legal liability or responsibility for the accuracy, completeness, or usefulness of any information, apparatus, product, or process disclosed, or represents that its use would not infringe privately owned rights. Reference herein to any specific commercial product, process, or service by trade name, trademark, manufacturer, or otherwise, does not necessarily constitute or imply its endorsement, recommendation, or favoring by the United States Government or any agency thereof. The views and opinions of authors expressed herein do not necessarily state or reflect those of the United States Government or any agency thereof.

\section{Availability}

This report is posted on the U.S. Department of Energy's Princeton Plasma Physics Laboratory Publications and Reports web site in Fiscal Year 2002. The home page for PPPL Reports and Publications is: http://www.pppl.gov/pub_report/

DOE and DOE Contractors can obtain copies of this report from:

U.S. Department of Energy

Office of Scientific and Technical Information

DOE Technical Information Services (DTIS)

P.O. Box 62

Oak Ridge, TN 37831

Telephone: (865) 576-8401

Fax: (865) 576-5728

Email: reports@adonis.osti.gov

This report is available to the general public from:

National Technical Information Service

U.S. Department of Commerce

5285 Port Royal Road

Springfield, VA 22161

Telephone: 1-800-553-6847 or

(703) 605-6000

Fax: (703) 321-8547

Internet: http://www.ntis.gov/ordering.htm 


\title{
Parametric Investigation of Miniaturized Cylindrical and Annular Hall
}

\author{
Thrusters \\ A. Smirnov ${ }^{*}$, Y. Raitses, and N. J. Fisch \\ Princeton University Plasma Physics Laboratory \\ P. O. Box 451, Princeton, NJ 08543
}

\begin{abstract}
Conventional annular Hall thrusters become inefficient when scaled to low power. An alternative approach, a 2.6- $\mathrm{cm}$ miniaturized cylindrical Hall thruster with a cusp-type magnetic field distribution, was developed and studied. Its performance was compared to that of a conventional annular thruster of the same dimensions. The cylindrical thruster exhibits discharge characteristics similar to those of the annular thruster, but it has a much higher propellant ionization efficiency. Significantly, a large fraction of multicharged xenon ions might be present in the outgoing ion flux generated by the cylindrical thruster. The operation of the cylindrical thruster is quieter than that of the annular thruster. The characteristic peak in the discharge current fluctuation spectrum at $50-60 \mathrm{kHz}$ appears to be due to ionization instabilities. In the power range 50-300 $\mathrm{W}$, the cylindrical and annular thrusters have comparable efficiencies (15$32 \%)$ and thrusts (2.5-12 mN). For the annular configuration, a voltage less than $200 \mathrm{~V}$ was not sufficient to sustain the discharge at low propellant flow rates. The cylindrical thruster can operate at voltages lower than $200 \mathrm{~V}$, which suggests that a cylindrical thruster can be designed to operate at even smaller power.
\end{abstract}

\footnotetext{
"Electronic mail: asmirnov@pppl.gov
} 


\section{INTRODUCTION}

Low-power propulsion devices, with small spacecraft mass, might enable new scientific and exploration space missions, such as multiple micro-spacecraft flying in constellations. ${ }^{1,2}$ The Hall thruster is a mature electric propulsion device at intermediate to high power, but it appears to be promising also for relatively low power primary propulsion on near-Earth missions ${ }^{3}$, such as orbit transfer and repositioning. At even lower power and smaller sizes, the cylindrical Hall thruster that we explore here may have advantages over the conventional annular Hall thruster.

In a conventional Hall thruster ${ }^{4}$, the axial electric and radial magnetic fields are applied in an annular channel. The magnetic field is large enough to lock the electrons in the azimuthal $E \times$ $B$ drift, but small enough to leave the ion trajectories almost unaffected. The thrust is generated in reaction to the axial electrostatic acceleration of ions. Ions are accelerated in a quasineutral plasma, so that no space-charge limitation is imposed on the achievable current and thrust densities. Conventional Hall thrusters designed for operation in 600-1000 W power range have outer channel diameter about $10 \mathrm{~cm}$, maximal value of the magnetic field radial component about $100 \mathrm{G}$, and applied discharge voltage $U_{d}=300 \mathrm{~V}$. The thruster efficiency, defined as a ratio of the kinetic energy flux at the thruster exit to the input electrical power, is about 50-60\%. Typical values of plasma parameters in a conventional Hall thruster are the following: electron density $n_{e} \sim 10^{11}-10^{12} \mathrm{~cm}^{-3}$, electron temperature $T_{e} \sim 10-20 \mathrm{eV}$, ion temperature $T_{i} \sim 1 \mathrm{eV}$, ion exhaust velocity $V_{i} \sim 16,000 \mathrm{~m} / \mathrm{s}$.

A smaller operating power of a Hall thruster implies either smaller discharge voltage or smaller discharge current. The degree to which the first option can be accommodated is limited by the necessity to keep the exhaust ion velocity high. The second option implies that the 
propellant flow rate should be decreased. In order to maintain high propellant utilization efficiency at low propellant flow rates, the thruster channel must be scaled down to preserve the ionization probability. Thus, according to Ref. (5), the acceleration region length, which is mainly determined by the magnetic field distribution, must be decreased linearly together with the channel sizes, while the magnetic field must be increased inversely to the scaling factor. However, the implementation of the latter requirement is technically challenging because of magnetic saturation in the miniaturized inner parts of the magnetic core. A linear scaling down of the magnetic circuit leaves almost no room for magnetic poles or for heat shields, making difficult the achievement of the optimal magnetic fields. Non-optimal magnetic fields result in enhanced power and ion losses, heating and erosion of the thruster parts, particularly the critical inner parts of the coaxial channel and magnetic circuit.

Currently existing low-power Hall thruster laboratory prototypes with channel diameters 2-4 cm operate at $100-300 \mathrm{~W}$ power levels with efficiencies in the range of $10-30 \% .{ }^{6-8}$ However, further scaling of the conventional geometry Hall thruster down to sub-centimeter size ${ }^{9}$ results in even lower efficiencies $(6 \%$ at power level of about $100 \mathrm{~W})$. The low efficiency might arise from a large axial electron current, enhanced either by magnetic field degradation due to excessive heating of the thruster magnets or by electron collisions with the channel walls. Thus, miniaturizing the conventional annular Hall thruster does not appear to be straightforward.

The cylindrical Hall thruster suggested in Ref. (10) features a channel with a short annular region and longer cylindrical region, and a cusp-type magnetic field distribution (see Fig. 1a). Having larger volume-to-surface ratio than the conventional annular thruster, and therefore, potentially smaller wall losses in the channel, the cylindrical Hall thruster should suffer lower erosion and heating of the thruster parts. This makes the concept of a cylindrical Hall thruster 
very promising for low-power applications.

A relatively large $9 \mathrm{~cm}$ diameter version of the cylindrical thruster exhibited performance comparable with conventional annular Hall thrusters in the sub-kilowatt power range ${ }^{10}$. In the present work we developed and studied a miniature $2.6 \mathrm{~cm}$ diameter cylindrical Hall thruster. In order to understand the physics of cylindrical Hall thrusters better and to examine the attractiveness of the cylindrical approach for low-power Hall thruster scaling, we compared the performance of the 2.6-cm cylindrical Hall thruster to that of the conventional annular thruster with the same channel diameter and length. Thruster ac and dc electrical measurements, as well as total ion flux and thrust measurements were performed. It was found that the cylindrical thruster has unusually high propellant ionization efficiency, compared to conventional Hall thrusters. The ratio of the total ion current to the effective propellant mass flow current, in the case of cylindrical configuration, could exceed unity, which clearly indicates the presence of multi-charged Xe ions in the ion flux generated by the thruster. The discharge in the cylindrical thruster was also found to be somewhat quieter than that in the annular thruster: The amplitude of oscillations in the frequency range $10-100 \mathrm{kHz}$ was relatively lower for the cylindrical configuration. However, the spectrum of discharge current oscillations of the cylindrical thruster exhibits a pronounced peak at about $50-60 \mathrm{kHz}$, which may be due to ionization instabilities. ${ }^{11}$ The higher ionization efficiency and quieter operation of the cylindrical thruster suggest that the underlying physics of the cylindrical design may differ significantly from that of the annular design.

The paper is organized as follows: In Sec. II the experimental setup is described. In Sec. III we describe the experimental results and discuss their implications. In Sec. IV we summarize our main conclusions. 


\section{EXPERIMENTAL SETUP}

A 2.6-cm cylindrical Hall thruster shown in Fig. 1 was scaled down from a $9 \mathrm{~cm}$ cylindrical Hall thruster to operate at about $200 \mathrm{~W}$ power level. ${ }^{12}$ Similar to the large thruster, this miniaturized cylindrical thruster consists of a Boron-Nitride ceramic channel, an annular anode, which serves also as a gas distributor, two electromagnetic coils, and a magnetic core. Field lines of the cusp-type magnetic field intersect the ceramic channel walls. The electron drift trajectories are closed. Magnetic field lines form equipotential surfaces, with $E=-v_{e} \times B$. Ion thrust is generated by the axial component of the Lorentz force, proportional to the radial magnetic field and the azimuthal electron current.

The cylindrical channel features a short annular region, approximately $1 \mathrm{~cm}$ long, and a longer cylindrical region. The total length of the channel is $2.6 \mathrm{~cm}$. The length of the annular region was chosen so as to provide high ionization of the working gas at the boundary of the annular and the cylindrical regions. The outer and the inner diameters of the channel are $2.6 \mathrm{~cm}$ and $1.4 \mathrm{~cm}$, respectively.

The thruster design allows one to vary the thruster geometry. By extending the central pole of the magnetic core and the central ceramic piece up to the exit plane of the channel, the cylindrical thruster can be converted to the conventional annular one. In this study we investigated two thruster configurations, namely, cylindrical with the dimensions specified above, and annular with the same channel outer and inner diameters, and length. The overall diameter and the thruster length are both $7 \mathrm{~cm}$.

Two electromagnetic coils are connected to separate power supplies. The currents in the 
coils are co-directed in the conventional configuration and counter-directed in the cylindrical configuration to produce cusp magnetic field with a strong radial component in the channel. Fig. 2 shows results of simulations of the magnetic field distribution for the annular and the cylindrical thrusters. The magnetic field was measured inside both these thrusters with a miniature Hall probe with dimensions $1.5 \mathrm{~mm} \times 1.5 \mathrm{~mm}$. The results of these measurements and simulations are in a good agreement.

For example, for the operating currents of $1.4 \mathrm{~A}$ in the back coil and $0.9 \mathrm{~A}$ in the front coil, the maximum radial magnetic field is $400 \mathrm{G}$ at the inner wall near the exit of the annular channel. In the cylindrical configuration, the radial magnetic field reaches its maximum, which is about $700 \mathrm{G}$, a few millimeters from the anode near the inner wall of the short annular part and then reduces towards the thruster exit.

The experiments were curried out in a $0.4-\mathrm{m}^{3}$ vacuum chamber, equipped with a turbo molecular pumping system (PPPL Small Hall Thruster facility). The measured pumping speed reached $\sim 1700 \pm 3001 / \mathrm{s}$ for Xe. The working background pressure of Xe was about $7 \times 10^{-5}$ Torr for the total propellant flow rate of $0.8 \mathrm{mg} / \mathrm{s}$. Uncertainty in the determining of the pumping speed was caused by discrepancies in the readings of two Bayard-Alpert tabulated ion gauges used to measure the background pressure. Two commercial flow controllers, $0-10 \mathrm{sccm}$ and 0-15 sccm, volumetrically calibrated in the flow rate range of 1-10 sccm, supplied research grade Xe gas to the anode and the cathode, respectively. A commercial HeatWave plasma source was used as a cathode-neutralizer. The cathode flow rate of Xe was held at $0.2 \mathrm{mg} / \mathrm{s}$ for all the experiments.

The total ion flux coming from the thruster and the plume angle were measured by a movable electrostatic graphite probe with a guarding sleeve. Graphite was chosen as a probe 
material because of its extremely low sputtering coefficient for Xe ions with energies lower than or about $500 \mathrm{eV}$. The probe could be rotated in the vertical plane \pm 90 deg relatively to the thruster exit. The probe collecting surface always points at the thruster center. The distance between the probe and the thruster center is $14 \mathrm{~cm}$. Yet another probe mounted on the same movable arm was used to measure the flux of backstreaming ions. The second probe is horizontally shifted about $2 \mathrm{~cm}$ away from the first one, and its collecting surface points out from the thruster.

Thrust measurements were performed in the Electric Propulsion and Plasma Dynamics Laboratory (EPPDL) at Princeton University. The EPPDL thrust stand ${ }^{13}$ was designed to measure accurately impulse bits for pulsed plasma thrusters (PPTs) within the range of $10^{-4}-10$ Ns. However, it was also predicted to be capable of measuring low steady state thrust, as low as $20 \mu N$.

The thruster was mounted on a swinging arm thrust stand. ${ }^{14}$ Fig. 3 shows the 2.6-cm annular Hall thruster attached to the arm. The thrust arm was mounted with two flexural pivots. Thrust arm displacement from the equilibrium position was measured by a linear voltage differential transformer.

During steady-state thruster operation, the thrust is directly proportional to the displacement of the arm:

$$
T=k_{\text {eff }}\left(x-x_{\text {equil }}\right)
$$

where $k_{\text {eff }}$ is the effective spring constant of the thrust stand. The effective spring constant is due to torsion exerted in the pivots, as well as restoring forces produced by the thruster wiring and 
the flexible silicon gas line (see Fig. 3), which connect the thruster with a fixed rigid part of the stand. In the present setup, it is impossible to eliminate the contribution of the wiring and the gas line to the effective spring constant. Although experimentally minimized, this contribution was of the order of the torsional spring constant of the flexural pivots.

It is worth mentioning that, for the same discharge voltage, coil currents and propellant flows, values of the discharge current measured at the EPPDL vacuum facility ${ }^{13}$ were generally about $10 \%$ lower than those measured at the PPPL Small Hall Thruster facility. This apparently was due to the fact that the operating background pressure of Xe (about $1 \times 10^{-5}$ Torr for the total propellant flow rate of $0.8 \mathrm{mg} / \mathrm{s}$ ) was typically 5-7 times lower than that at the PPPL facility.

\section{EXPERIMENTAL RESULTS AND DISCUSSION}

\section{A. Ion current and V-I characteristics}

The 2.6-cm Hall thruster was operated at the discharge voltages of 150 - $300 \mathrm{~V}$ and Xe mass flow rates of $0.4-0.8 \mathrm{mg} / \mathrm{s}$. The cathode was placed close to the thruster exit at the 30 degrees angle to the thruster axis (Fig. 1). Thruster operation in the cylindrical and annular configurations is shown in Fig. 4.

Illustrative curves of voltage-versus-current characteristics measured for each thruster configuration are shown in Fig. 5a. At given discharge voltage and propellant flow rate, the discharge current, and, consequently, the input power in the cylindrical thruster, are both larger than those in the annular thruster by factor of 1.5-2. However, the current utilization efficiency, which is the ratio of the ion current at the exit plane of the thruster to the total discharge current, 
differs on average by about $10 \%$ only at voltages of $250-300 \mathrm{~V}$ (Fig. 5b). The reason for this is an exceptionally high propellant ionization efficiency of the cylindrical thruster.

The thruster ionization efficiency is characterized by a so-called propellant utilization coefficient $\eta_{I}-$ a ratio of the total ion current $I_{i}$ at the thruster exit plane to the propellant flow rate $\mu$ measured in units of electric current. Namely, $\eta_{I}=I_{i} M / e \mu$, where $M$ is a mass of a propellant gas atom, $e$ is the electron charge. In Fig. $6 \eta_{I}$ is plotted vs. discharge voltage for the cylindrical and annular configurations. Propellant utilization for the cylindrical configuration can be seen to be much higher than that for the annular one. It increases with the discharge voltage and exceeds unity at high voltages, which implies a presence of Xe ions in charge states higher than +1 in the ion flux.

The increase in propellant utilization in the cylindrical configuration might be explained by ionization enhancement due to an increase in the electron density. As seen from Fig 5b, the electron current to the anode in the cylindrical thruster is larger than in the annular. On the other hand, the electron mobility across the magnetic field must be lower in the cylindrical configuration, because the radial component of the magnetic field is typically $1.5-2$ times larger than that in the annular one. Therefore, the electron density in the channel is expected to be higher in the cylindrical configuration. Simple estimates show that a $25 \%$ increase in the propellant utilization (see Fig. 6) requires only about twofold increase in the electron density. However, an increase in the radial magnetic field in a conventional annular thruster does not lead to a corresponding increase in the electron density because of the onset of strong high-frequency discharge current oscillations. ${ }^{11}$

The fact that the ion flux produced by the thruster can contain a substantial portion of multiply charged $\mathrm{Xe}$ ions is of particular interest. It is worth mentioning that even in 
conventional Hall thrusters, where the propellant utilization coefficient is typically 0.8-0.9, an ion flux can have rather large fractions of $\mathrm{Xe}^{2+}$ and $\mathrm{Xe}^{3+}$ ions. ${ }^{15}$ The major factor in multicharged ions formation in a Hall thruster is the ion residence time in the channel. Simple estimates show that the time of flight of a $\mathrm{Xe}^{+}$ion through a channel is much smaller than the time of ionization to higher charge states. Indeed, one expects a plasma in a miniaturized Hall thruster to have electron density of about $10^{12} \mathrm{~cm}^{-3}$ and electron temperature of $10-20 \mathrm{eV}{ }^{16}$ For example, for $T_{e} \sim 20 \mathrm{eV}$ the rate coefficient for single electron impact ionization $\mathrm{Xe}^{+1} \rightarrow \mathrm{Xe}^{+2}$ is about $k_{1,2} \sim 4 \times 10^{-8} \mathrm{~cm}^{3} / \mathrm{s} .{ }^{17}$ Therefore, even for a moderately energetic ion with $E_{i}=50 \mathrm{eV}$, the time of flight through a channel with length $L=3 \mathrm{~cm} \tau_{f} \sim L / V_{i} \sim 4 \times 10^{-6} \mathrm{~s}$ is approximately an order of magnitude smaller than the ionization time $\tau_{1,2} \sim\left(n_{e} k 1,2\right)^{-1} \sim 3 \times 10^{-5}$ s. Thus, in this regime, we expect the number of ionization events to scale linearly with the residue time. The presence of a significant number of multicharged ions in the outgoing ion flux might be an indication of complex ion dynamics (possibly, non-straight trajectories, trapping by ambipolar potential, etc.), which increase the ion life time inside the channel. Formation of an ion charge state distribution in a Hall thruster discharge is worth studying further.

\section{B. Discharge oscillations}

Typical spectra of the discharge current oscillations are shown in Fig. 7. Although the amplitude of oscillations is relatively lower for the cylindrical configuration, the discharge at low

propellant flow rates is not as quiet as it was found to be in the large $9 \mathrm{~cm}$ cylindrical thruster. ${ }^{10}$ The characteristic peak at frequencies $50-60 \mathrm{kHz}$ may be due to the ionization instability, whic $\mathrm{h}$ appears because of the depletion of neutral atoms in the ionization and acceleration regions. ${ }^{11}$ 
The characteristic frequency of these oscillations scales as $f \sim v_{n} / L_{i}$, where $v_{n}$ is the thermal speed of neutral atoms and $L_{i}$ is the ionization region length. Apparently, the characteristic frequency, which was typically about $20 \mathrm{kHz}$ for a $9-\mathrm{cm}$ annular Hall thruster, ${ }^{10}$ almost triples as $\mathrm{L}_{i}$, together with the thruster sizes, are reduced by factor of about 3 .

\section{Thrust and efficiency}

As mentioned above, the thrust stand had not been specifically designed to suit the experimental environment of a steady-state Hall thruster operation. Thruster operation showed that the heat generated by the thruster brought about a weak long-timescale thermal drift of the thrust stand equilibrium position. The larger the thruster operating power was, the more visible this effect became. However, it was experimentally found that the thrust stand moment of inertia remained almost unaffected by a temperature change due to the thruster operation.

In order to minimize the uncertainty of the thrust measurements caused by the equilibrium position drift, a procedure to determine an 'instantaneous' equilibrium position and

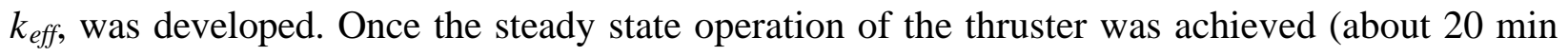
from the ignition of the discharge), the discharge voltage, the coil power, and the gas flow to the anode and cathode were turned off, and oscillations of the thrust arm position $x(t)$ were recorded (Fig. 8).

The thrust arm position $x_{0}$ corresponding to the firing thruster was determined from averaging $x(t)$ over a 2 -second interval immediately before turning the thruster off. The instantaneous equilibrium position $x_{\text {equil }}$ together with $k_{\text {eff }}$ were determined from fitting approximately half of the oscillations period right after the turning off with a damped linear 
oscillator response function. ${ }^{13}$ The thrust was calculated then according to Eq. (1). For each set of operating parameters, the thrust measurement was repeated several times to minimize the statistical error. This measurement procedure ensured good repeatability of results.

Figure 9 shows measured thrust versus discharge voltage and efficiency versus input power for different anode flow rates for the cylindrical and annular configurations of 2.6-cm Hall thruster. In all regimes but one, the estimated error bars on thrust and efficiency are $\pm 3 \%$ and \pm $6 \%$, respectively, which is comparable with typical values of errors for most of the low-thrust measurements. ${ }^{6,7}$ In the case of cylindrical configuration with anode flow rate of $0.7 \mathrm{mg} / \mathrm{s}$ the error bars are $\pm 6 \%$ for thrust and $\pm 12 \%$ for efficiency. These relatively larger measurement errors are due to the more pronounced thrust stand thermal drift, observed at high operating power, and, partly, to the anode unstable operation in this particular regime. Anode unstable operation was supposedly caused by the anode overheating.

Measured thrust ranges from about $3 \mathrm{mN}(200 \mathrm{~V}, 86 \mathrm{~W})$ to $12 \mathrm{mN}(300 \mathrm{~V}, 320 \mathrm{~W})$ for the cylindrical configuration, and from about $2.5 \mathrm{mN}(200 \mathrm{~V}, 63 \mathrm{~W})$ to $10 \mathrm{mN}(300 \mathrm{~V}, 225 \mathrm{~W})$ for the annular configuration. For any given discharge voltage and anode flow rate in the range of parameters investigated, the thrust generated in the cylindrical configuration is larger than that in the annular configuration. This is another indication that the cylindrical configuration has a better propellant ionization capability (see Fig. 6).

It is worth mentioning that the cylindrical thruster can be operated at the discharge voltage lower than $200 \mathrm{~V}$, while for the annular configuration such voltage is not sufficient to sustain the discharge at low propellant flow rates. In Fig. 9, the voltage is kept at least at $200 \mathrm{~V}$ only in order to make a comparison between the two configurations. 
The average ion exhaust velocity, defined as the ratio of the thrust to the anode propellant flow rate $V_{\mathrm{ex}}=T / \mu$, ranges from $7 \mathrm{~km} / \mathrm{s}\left(\mu=0.4 \mathrm{mg} / \mathrm{s}, U_{d}=200 \mathrm{~V}\right)$ to $14.5 \mathrm{~km} / \mathrm{s}(\mu=0.7 \mathrm{mg} / \mathrm{s}$, $\left.U_{d}=300 \mathrm{~V}\right)$ for the annular configuration, and from $8 \mathrm{~km} / \mathrm{s}\left(\mu=0.4 \mathrm{mg} / \mathrm{s}, U_{d}=200 \mathrm{~V}\right)$ to $17.4 \mathrm{~km} / \mathrm{s}$ $\left(\mu=0.7 \mathrm{mg} / \mathrm{s}, U_{d}=300 \mathrm{~V}\right)$ for the cylindrical configuration. The values of $V_{\mathrm{ex}}$ attainable with a 2.6$\mathrm{cm}$ cylindrical thruster, in the power range above $250 \mathrm{~W}$, even exceed those typical of moderatesized conventional Hall thrusters (about $16 \mathrm{~km} / \mathrm{s}$ ).

The efficiency $\eta$ was calculated, using the measured thrust $T$, flow rate $\mu$ and power $P$, as $\eta=T^{2} / 2 \mu P$. The cathode power and propellant flow and the magnet losses were not taken into account. Therefore, the efficiency plotted in Fig. $9 \mathrm{~b}$ is a so-called 'anode' efficiency. As can be seen from the graphs, the cylindrical and annular thrusters have comparable efficiencies. This, in principle, gives an opportunity to develop a low-power Hall thruster capable of generating a variable thrust at given efficiency and thruster power. The use of a variable-thrust thruster is required for optimization of a propellant expenditure on satellites. ${ }^{18}$ Thrust variation can be achieved in the $2.6 \mathrm{~cm}$ Hall thruster by changing the length of the central magnetic pole and channel piece. At constant power, one can increase the thrust (and decrease the ion exhaust velocity) by converting the thruster from the cylindrical to the annular configuration. For example, at power of about $120 \mathrm{~W}$ (see Fig. 9a and 9b), the transition between $\mu=0.4 \mathrm{mg} / \mathrm{s}$ and $U_{d}=250 \mathrm{~V}$ in the cylindrical configuration and $\mu=0.6 \mathrm{mg} / \mathrm{s}$ and $U_{d}=200 \mathrm{~V}$ in the annular configuration decreases efficiency by less than $2 \%$, while the increase in thrust is $21 \%$.

\section{CONCLUSIONS}


Annular conventional Hall thrusters become inefficient when scaled to small sizes because of the large surface-to-volume ratio and the difficulty in miniaturizing the magnetic circuit. An alternative approach, which may be more suitable for scaling to low power, is a cylindrical Hall thruster. A 2.6-cm miniaturized cylindrical Hall thruster was developed and operated in a broad range of operating parameters. Its performance was compared to that of a conventional annular thruster of the same dimensions. Several interesting effects were observed.

The ion flux and thrust measurements showed that propellant ionization efficiency of the cylindrical thruster is much higher than that of the annular. Therefore, gases or gas mixtures that are harder to ionize than Xe may be used as a propellant; for example, one can use argon to generate larger ion exhaust velocities. In the cylindrical thruster, at high propellant flow rates, a significant fraction of multicharged xenon ions can be present in the outgoing ion flux. This may indicate complex ion dynamics that increase the ion life time in the channel. The formation of multicharged ions in a cylindrical Hall thruster discharge, which can differ significantly from that in an annular thruster, is a subject of ongoing research.

Discharge characteristics of the cylindrical thruster are comparable to those measured for the annular thruster. Although relatively quieter operation of the cylindrical thruster was observed, the discharge at low propellant flows is not as quiet as it was found to be in the large 9-cm cylindrical thruster. The characteristic peak at frequencies $50-60 \mathrm{kHz}$ may be due to the ionization instability, which frequency approximately triples as the thruster sizes are reduced by factor of 3 .

At given discharge voltage and propellant flow rate, the discharge current and input power of the cylindrical thruster are higher than those of the annular one. The higher power and current would tend to erode the thruster faster; on the other hand, the cylindrical thruster has a lower 
surface-to-volume ratio and fewer inner parts. The lifetime comparison, therefore, remains an open question.

In the power range 50-300 $\mathrm{W}$, the cylindrical and annular thrusters have comparable efficiencies $(\eta=15-32 \%)$ and thrusts $(T=2.5-12 \mathrm{mN})$. Since these configurations may be controlled electronically, it may be possible to develop an efficient low-power Hall thruster with a variable thrust.

The values of efficiency for both configurations are comparable to those of other currently existing Hall microthrusters. For exa mple, BHT-200-X2B ${ }^{6}$ has channel diameter $d=2.1 \mathrm{~cm}$ and operates at power $\mathrm{P}=100-300 \mathrm{~W}$ with efficiency $\eta=20-45 \%$, SPT- $30{ }^{7}$ has $d=3 \mathrm{~cm}, \mathrm{P}=100-260$ $\mathrm{W}$, and $\eta=16-34 \%$.

For the annular configuration, a voltage less than $200 \mathrm{~V}$ was not sufficient to sustain the discharge at low propellant flow rates. However, the cylindrical thruster can operate at low voltages $\left(U_{d}<200 \mathrm{~V}\right)$. Operation at low voltage is important for three reasons: (i) certain missions may require lower ion exhaust velocity; (ii) voltages lower than $200 \mathrm{~V}$ may be accommodated by direct drive power, which could simplify enormously the power processing unit on a small satellite; (iii) the operation at low voltage implies that further miniaturization may be possible, thereby allowing even lower power operation.

Finally, it is important to note that the operating conditions attained here for the cylindrical thruster have not been completely optimized. There is a considerable flexibility in the magnetic configuration, and that has not been fully addressed. Furthermore, there may be added flexibility in the use of segmented electrodes in order to impose a potential profile, as was done in the case of the annular thruster ${ }^{19,20}$. Any further control of the electric field profile in the cylindrical thruster is likely to allow enhanced performance, because the operation of this thruster is likely 
particularly sensitive to the location of the acceleration region, both radially and axially.

\section{Acknowledgments}

The authors would like to thank Prof. Edgar Choueiri for the provided opportunity to work with the EPPDL thrust stand, Kurt Polzin for his assistance in the thrust measurements, and David Staack for help in the experiments at the PPPL facility.

This work was supported by grants from AFOSR, DARPA, and USDOE Contract AC02-76CH03073. 


\section{References}

1. R.M. Jones, Journal of the British Interplanetary Society, 42(10), 2588 (1989)

2. R.L. Ticker, D. McLennan, Proceedings of IEEE Aerospace Conference, Big Sky, MN, 2001

3. J. Mueller, in Micropropulsion for Small Spacecraft, edited by M.M. Micci and A.D. Ketsdever (AIAA Progress in Astronautics and Aeronautics, 2000), Vol. 187, p. 45.

4. A.I. Morozov and V.V. Savelyev, in Review of Plasma Physics, edited by B.B. Kadomtsev and V.D. Shafranov (Consultants Bureau, New York, 2000), Vol. 21, p. 203.

5. J. Ashkenazy, Y. Raitses, and G. Appelbaum, Proceedings of the $2^{\text {nd }}$ International Spacecraft Propulsion Conference, Holland, 1997.

6. V. Hruby, J. Monheiser, B. Pote, C. Freeman, and W. Connolly, IEPC paper 99-092, $26^{\text {th }}$ International Electric propulsion Conference, Ktakyushu, Japan, June 1999.

7. D. Jacobson and R. Jankovsky, AIAA paper 98-3792, 34th Joint Propulsion Conference, Cleveland, OH, July 1998.

8. O. Gorshkov, AIAA paper 98-3929, 34th Joint Propulsion Conference, Cleveland, OH, July 1998. 
9. V. Khayms and M. Martinez-Sanches, in Micropropulsion for Small Spacecraft, edited by M.M. Micci and A.D. Ketsdever (AIAA Progress in Astronautics and Aeronautics, 2000), Vol. 187, p. 45.

10. Y. Raitses and N.J. Fisch, Phys. Plasmas 8, 2579 (2001).

11. J.P. Boeuf and L. Garrigues, J. Appl. Phys. 84, 3541 (1998).

12. A. Smirnov, Y. Raitses, and N.J. Fisch, IEPC paper $01-038,27^{\text {th }}$ International Electric propulsion Conference, Pasadena, CA, October 2001.

13. E.A. Cubbin, J.K. Ziemer, E.Y. Choueiri, and R.G. Jahn, Rev. Sci. Instrum. 68 (6), 2339 (1997).

14. Full description of the thrust stand, the calibration procedure, as well as the measurement procedure for PPTs are given in Ref. (13). In the present paper we describe the thrust stand features relevant to a steady state Hall thruster operation only.

15. L.B. King and A.D. Gallimore, AIAA paper 98-3641, 34th Joint Propulsion Conference, Cleveland, OH, July 1998.

16. A. Bishaev and V. Kim, Sov. Phys. Tech. Phys 23, 1055 (1978).

17. E.W. Bell, N. Djuric, and G.H. Dunn, Phys.Rev A 48(6), 4286 (1993).

18. J.P. Marek, in Optimal Space Trajectories, Elsevier, Amsterdam, 1979, pp. 7-19, 38.

19. Y. Raitses, L. A. Dorf, A. A. Litvak, and N. J. Fisch, J. Appl. Phys. 88, 1263 (2000).

20. N. J. Fisch, Y. Raitses, L. A. Dorf, and A. A. Litvak, J. Appl. Phys. 89, 2040 (2001). 


\section{Figure Captions}

Fig. 1.

a) Schematic of a cylindrical Hall thruster.

b) The 2.6-cm cylindrical Hall thruster.

Fig. 2.

Magnetic circuit and magnetic field distribution for the annular (a) and the cylindrical (b) thrusters. The channel outer diameter is $2.6 \mathrm{~cm}$.

Fig. 3.

$2.6 \mathrm{~cm}$ annular Hall thruster mounted on the thrust stand.

Fig. 4.

Thruster operation in the annular (a) and cylindrical (b) configurations.

Fig. 5.

a) Discharge voltage versus current characteristics for the $2.6-\mathrm{cm}$ cylindrical (C) and annular (A) thrusters (as measured at the PPPL experimental facility). The cathode flow rate is $0.2 \mathrm{mg} / \mathrm{s}$.

b) Ratio of the ion current at the exit of the thruster to the discharge current versus the discharge voltage. 
Fig. 6.

Propellant utilization coefficient versus discharge voltage for the 2.6-cm cylindrical (C) and $\operatorname{annular}(\mathrm{A})$ thrusters

Fig. 7.

Spectra of discharge current oscillations for the annular and cylindrical thrusters at $U_{d}=300 \mathrm{~V}$ and anode flow rate of $0.4 \mathrm{mg} / \mathrm{s}$.

Fig. 8.

An exemplary trace of thrust arm position vs. time. At $\approx 196.3 \mathrm{~s}$, the thruster was turned off. Time interval from $198 \mathrm{~s}$ to $203 \mathrm{~s}$ is used for curve fitting with a damped linear oscillator response function (solid line) to determine the instantaneous equilibrium position. A 2-second interval (solid line) before the turning off is used to determine the arm displacement caused by the produced thrust.

Fig. 9.

a) Measured thrust vs. discharge voltage and b) efficiency as a function of input power for different anode flow rates for the 2.6-cm cylindrical (C) and annular (A) thrusters. The estimated error bars on thrust and efficiency are $\pm 3 \%$ and $\pm 6 \%$, respectively, for all regimes except for the case of cylindrical configuration with anode flow rate of $0.7 \mathrm{mg} / \mathrm{s}$, where the error bars are $\pm 6 \%$ for thrust and $\pm 12 \%$ for efficiency. 
Journal of Applied Physics

A. Smirnov et.al.

Fig. 1.
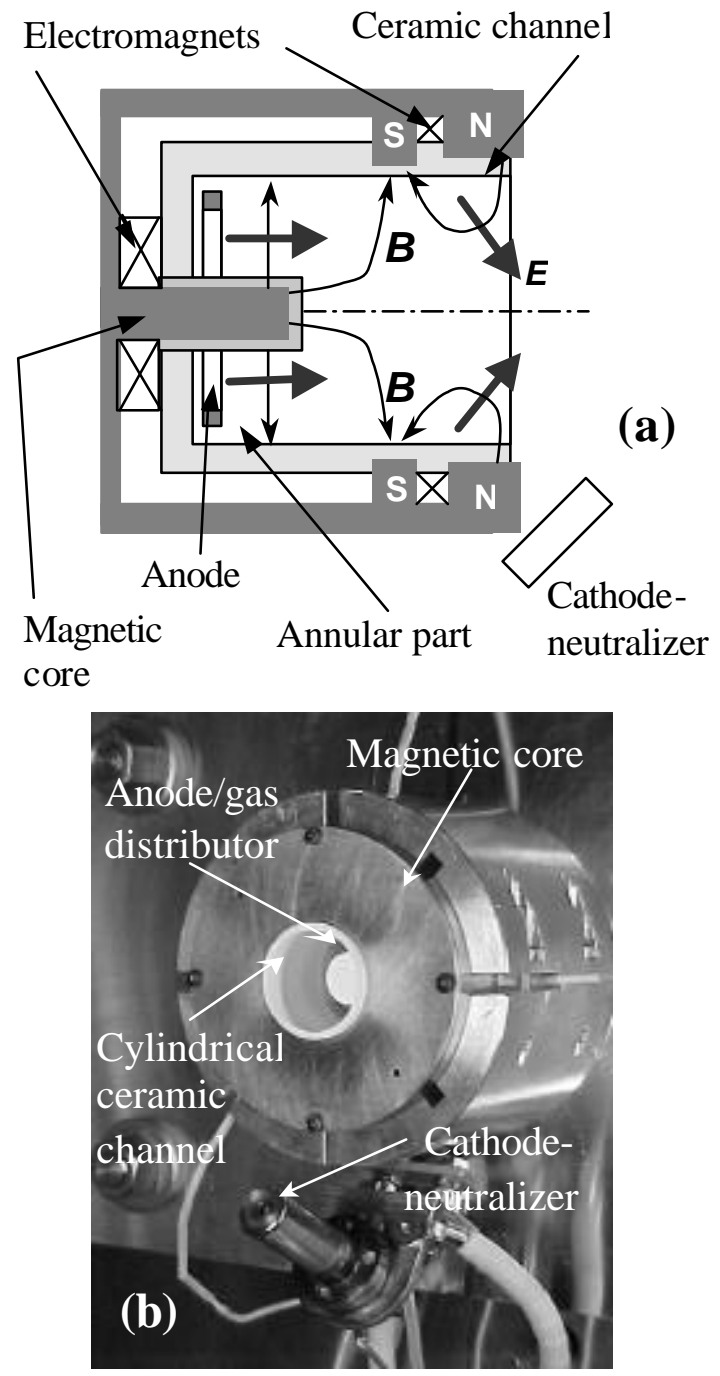
Journal of Applied Physics

A. Smirnov et.al.

Fig. 2.

(a)

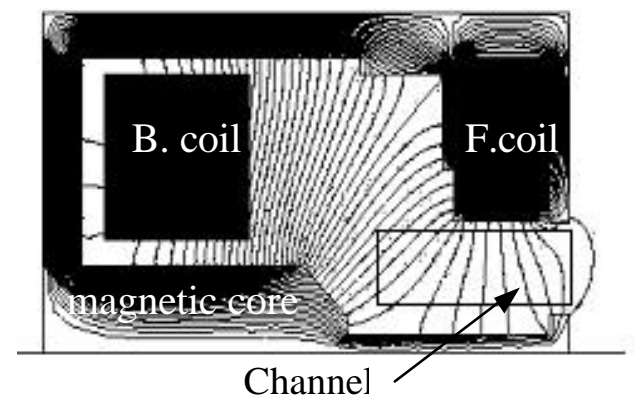

(b)

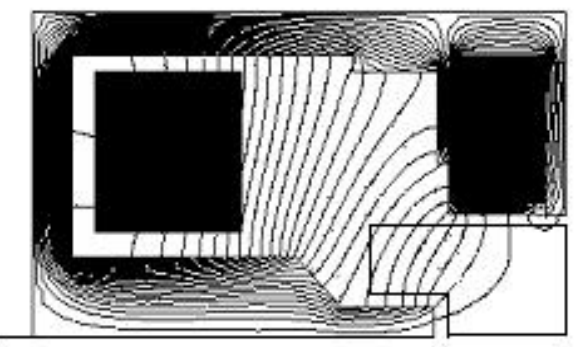

Thruster axis 
Journal of Applied Physics

A. Smirnov et.al.

Fig. 3.

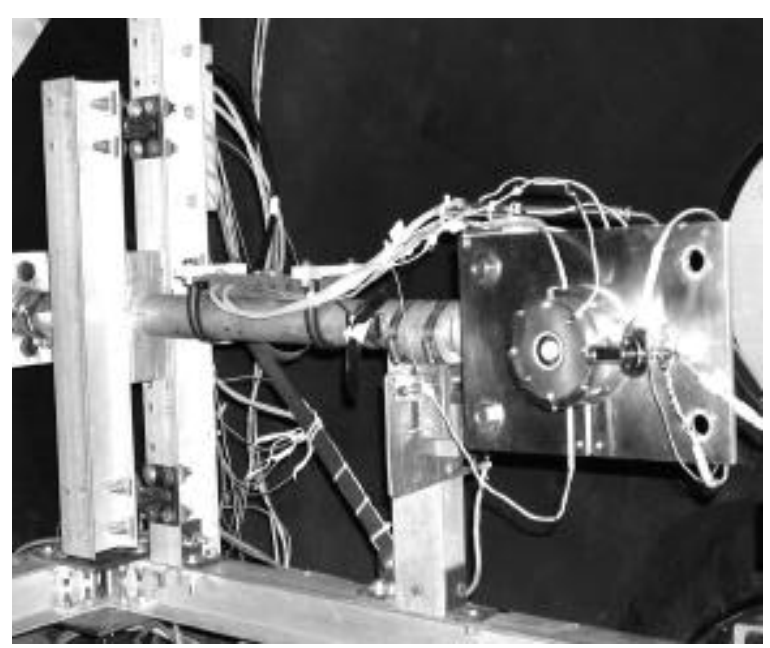


Journal of Applied Physics

A. Smirnov et.al.

Fig. 4.

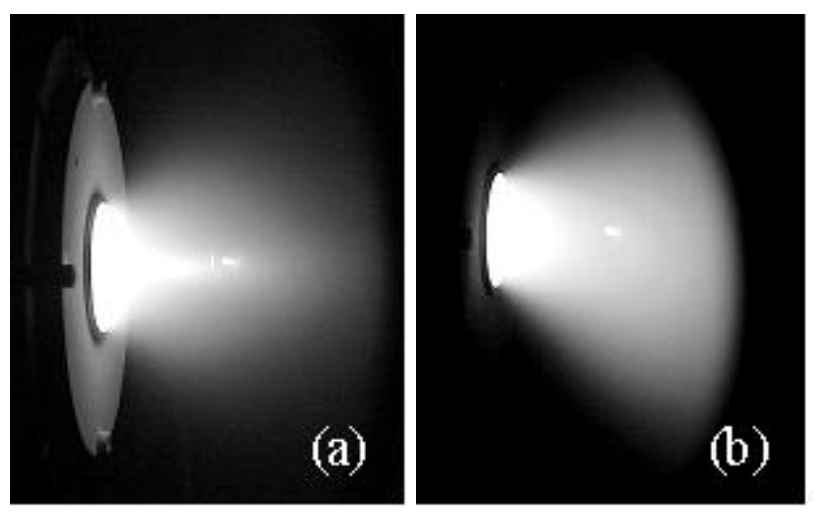


Journal of Applied Physics

A. Smirnov et.al.

Fig. 5.
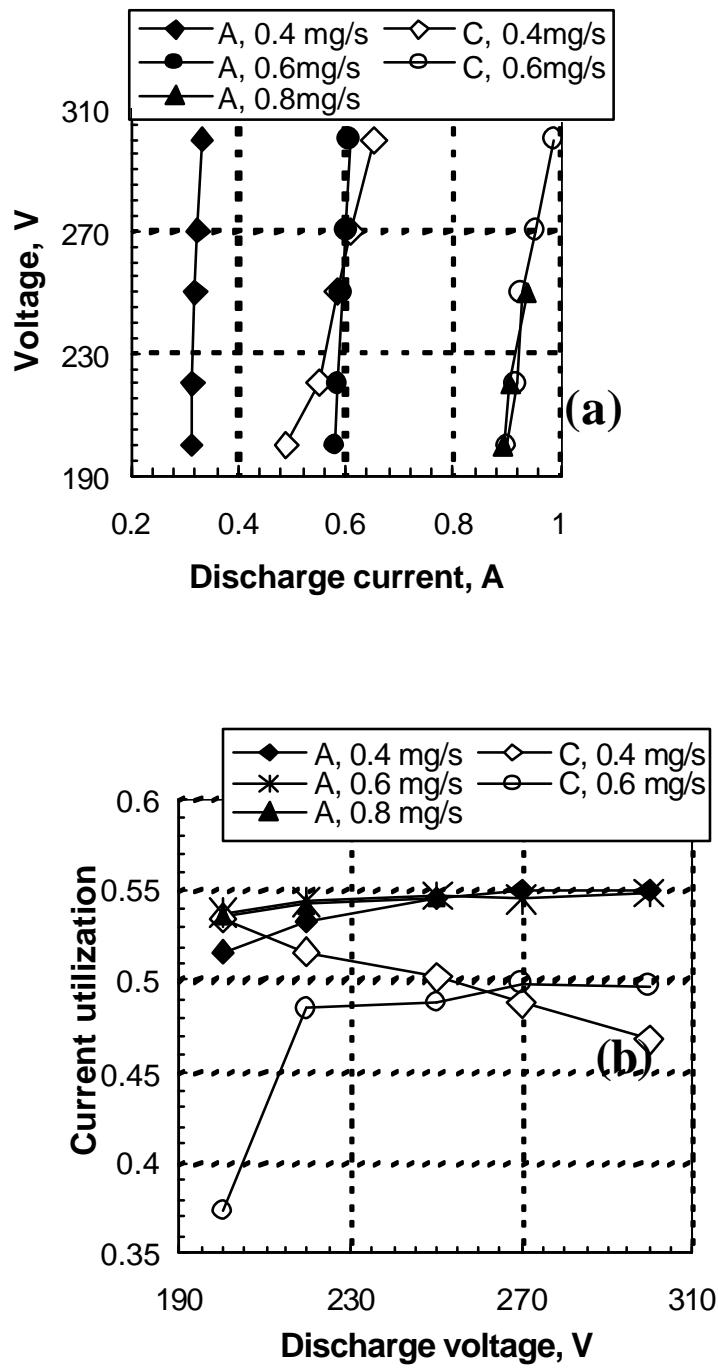
Journal of Applied Physics

A. Smirnov et.al.

Fig. 6.

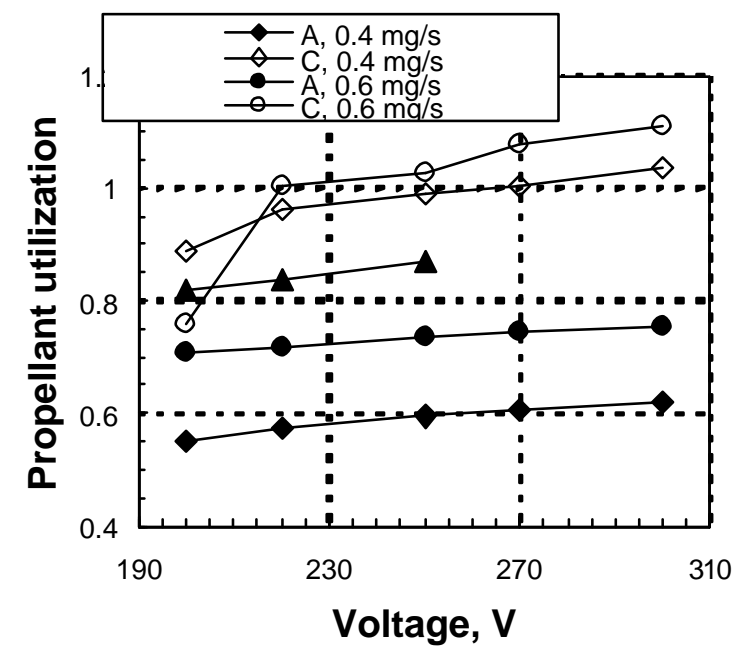


Journal of Applied Physics

A. Smirnov et.al.

Fig. 7.

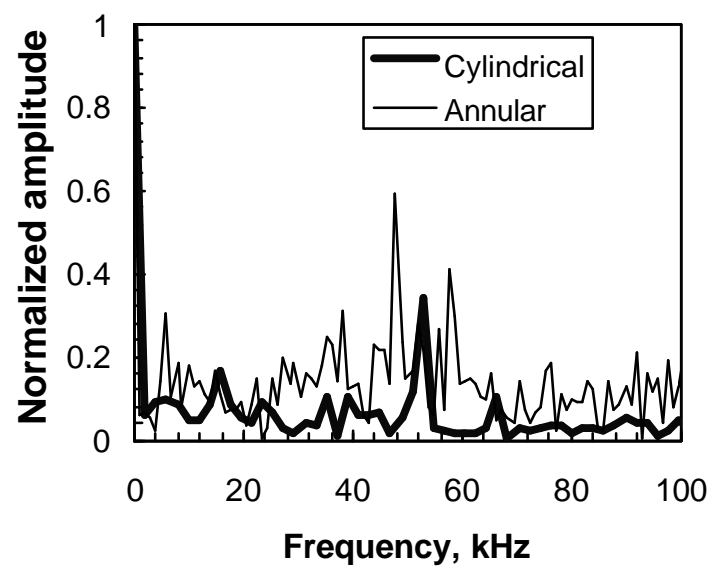


Journal of Applied Physics

A. Smirnov et.al.

Fig. 8.

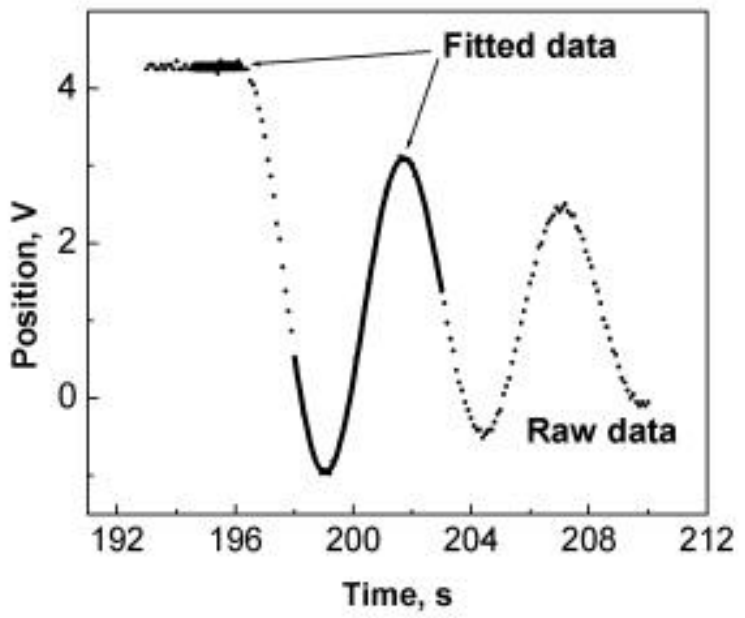


Journal of Applied Physics

A. Smirnov et.al.

Fig. 9.

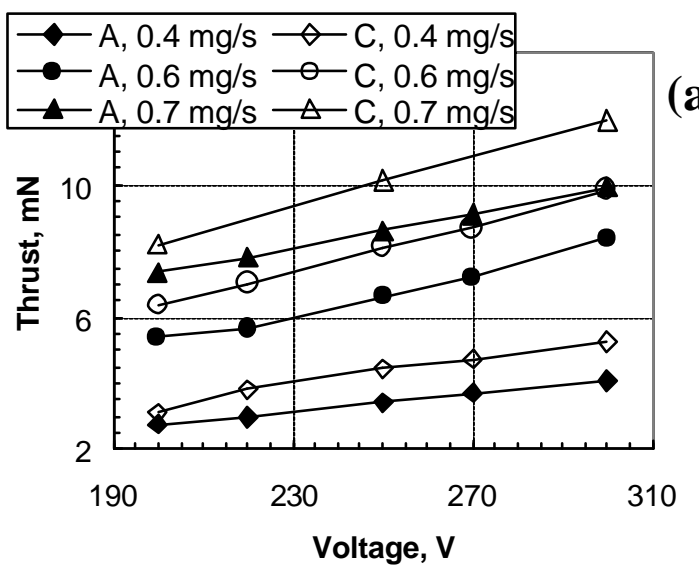

(a)

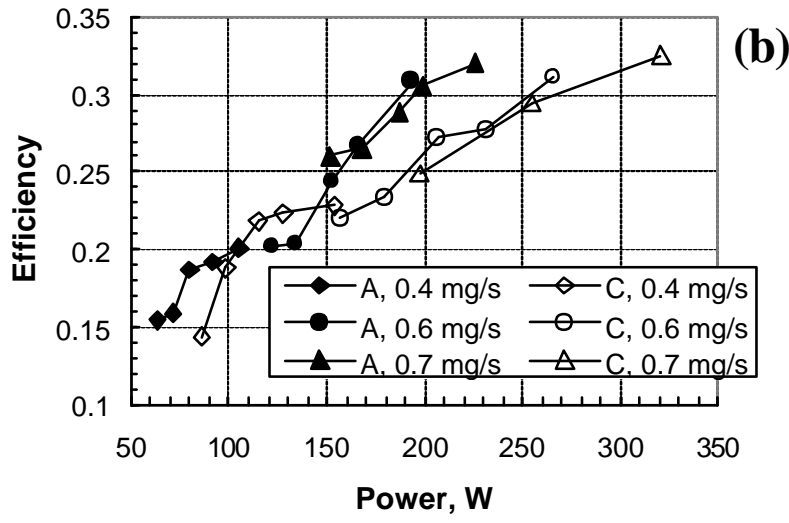




\section{External Distribution}

Plasma Research Laboratory, Australian National University, Australia

Professor I.R. J ones, Flinders University, Australia

Professor J oão Canalle, Instituto de Fisica DEQ/IF - UERJ , Brazil

Mr. Gerson O. Ludwig, Instituto Nacional de Pesquisas, Brazil

Dr. P.H. Sakanaka, Instituto Fisica, Brazil

The Librarian, Culham Laboratory, England

Library, R61, Rutherford Appleton Laboratory, England

Mrs. S.A. Hutchinson, JET Library, England

Professor M.N. Bussac, Ecole Polytechnique, France

Librarian, Max-Planck-Institut für Plasmaphysik, Germany

J olan Moldvai, Reports Library, MTA KFKI-ATKI, Hungary

Dr. P. Kaw, Institute for Plasma Research, India

Ms. P.J . Pathak, Librarian, Insitute for Plasma Research, India

Ms. Clelia De Palo, Associazione EURATOM-ENEA, I taly

Dr. G. Grosso, Instituto di Fisica del Plasma, Italy

Librarian, Naka Fusion Research Establishment, J AERI, J apan

Library, Plasma Physics Laboratory, Kyoto University, J apan

Research Information Center, National Institute for Fusion Science, J apan

Dr. O. Mitarai, Kyushu Tokai University, J apan

Library, Academia Sinica, Institute of Plasma Physics, People's Republic of China

Shih-Tung Tsai, Institute of Physics, Chinese Academy of Sciences, People's Republic of China

Dr. S. Mirnov, TRINITI, Troitsk, Russian Federation, Russia

Dr. V.S. Strelkov, Kurchatov Institute, Russian Federation, Russia

Professor Peter Lukac, Katedra Fyziky Plazmy MFF UK, Mlynska dolina F-2, Komenskeho Univerzita, SK-842 15 Bratislava, Slovakia

Dr. G.S. Lee, Korea Basic Science Institute, South Korea

Mr. Dennis Bruggink, Fusion Library, University of Wisconsin, USA

Institute for Plasma Research, University of Maryland, USA

Librarian, Fusion Energy Division, Oak Ridge National Laboratory, USA

Librarian, Institute of Fusion Studies, University of Texas, USA

Librarian, Magnetic Fusion Program, Lawrence Livermore National Laboratory, USA

Library, General Atomics, USA

Plasma Physics Group, Fusion Energy Research Program, University of California at San Diego, USA

Plasma Physics Library, Columbia University, USA

Alkesh Punjabi, Center for Fusion Research and Training, Hampton University, USA

Dr. W.M. Stacey, Fusion Research Center, Georgia Institute of Technology, USA

Dr. J ohn Willis, U.S. Department of Energy, Office of Fusion Energy Sciences, USA

Mr. Paul H. Wright, Indianapolis, Indiana, USA 
The Princeton Plasma Physics Laboratory is operated by Princeton University under contract with the U.S. Department of Energy.

\author{
Information Services \\ Princeton Plasma Physics Laboratory \\ P.O. Box 451 \\ Princeton, NJ 08543
}

Phone: 609-243-2750

Fax: 609-243-2751

e-mail: pppl_info@pppl.gov

Internet Address: http://www.pppl.gov 